\title{
Surface antigen phenotypes of hematopoietic stem cells from embryos and murine embryonic stem cells
}

Shannon L. McKinney-Freeman, Olaia Naveiras, Frank Yates, Sabine Loewer, Marsha Philitas, Matthew Curran, Peter J. Park and George Q. Daley

Updated information and services can be found at:

http://bloodjournal.hematologylibrary.org/content/114/2/268.full.html

Articles on similar topics can be found in the following Blood collections

Hematopoiesis and Stem Cells (3207 articles)

Information about reproducing this article in parts or in its entirety may be found online at:

http://bloodjournal.hematologylibrary.org/site/misc/rights.xhtml\#repub_requests

Information about ordering reprints may be found online at:

http://bloodjournal.hematologylibrary.org/site/misc/rights.xhtml\#reprints

Information about subscriptions and ASH membership may be found online at:

http://bloodjournal.hematologylibrary.org/site/subscriptions/index.xhtml

Blood (print ISSN 0006-4971, online ISSN 1528-0020), is published weekly by the American Society of Hematology, 2021 L St, NW, Suite 900,

Washington DC 20036.

Copyright 2011 by The American Society of Hematology; all rights reserved.

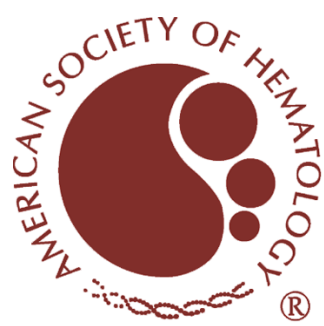




\title{
Surface antigen phenotypes of hematopoietic stem cells from embryos and murine embryonic stem cells
}

\author{
Shannon L. McKinney-Freeman, ${ }^{1-3}$ Olaia Naveiras, ${ }^{1-3}$ Frank Yates, ${ }^{1,4}$ Sabine Loewer, ${ }^{1-3}$ Marsha Philitas, $, 1,2,5$ \\ Matthew Curran, ${ }^{1-3}$ Peter J. Park, ${ }^{6}$ and George Q. Daley ${ }^{1-3,5}$ \\ 1'Division of Pediatric Hematology/Oncology, Manton Center for Orphan Diseases, Stem Cell Transplantation Program, Children's Hospital, Boston, MA; \\ ${ }^{2}$ Department of Biochemistry and Molecular Pharmacology, Harvard Medical School, Boston, MA; ${ }^{3 H a r v a r d ~ S t e m ~ C e l l ~ I n s t i t u t e, ~ C a m b r i d g e, ~ M A ; ~}{ }^{4} \mathrm{Human}$ \\ Embryonic Stem Cell Core Facility, Hopital Paul Brousse, Villejuif, France; ${ }^{5}$ Howard Hughes Medical Institute, Chevy Chase, MD; and ${ }^{6}$ Children's Hospital \\ Informatics Program, Boston, MA
}

\begin{abstract}
Surface antigens on hematopoietic stem cells (HSCs) enable prospective isolation and characterization. Here, we compare the cell-surface phenotype of hematopoietic repopulating cells from murine yolk sac, aorta-gonad-mesonephros, placenta, fetal liver, and bone marrow with that of HSCs derived from the in vitro differentiation of murine embryonic stem cells (ESCHSCs). Whereas c-Kit marks all HSC popu-
\end{abstract}

lations, CD41, CD45, CD34, and CD150 were developmentally regulated: the earliest embryonic HSCs express CD41 and CD34 and lack CD45 and CD150, whereas more mature HSCs lack CD41 and CD34 and express CD45 and CD150. ESC-HSCs express CD41 and CD150, lack CD34, and are heterogeneous for CD45. Finally, although CD48 was absent from all in vivo HSCs examined, ESC-HSCs were hetero- geneous for the expression of this molecule. This unique phenotype signifies a developmentally immature population of cells with features of both primitive and mature HSC. The prospective fractionation of ESC-HSCs will facilitate studies of HSC maturation essential for normal functional engraftment in irradiated adults. (Blood. 2009;114:268-278)

\section{Introduction}

Defining the repertoire of cell-surface molecules that enables hematopoietic stem cell (HSC) purification has been key to their detailed functional characterization. Phenotypic changes of HSCs can be correlated with changes in their cell cycle status, activation, and differentiation. ${ }^{1}$ As active sites of hematopoiesis transition during development from the yolk sac (YS) to the aorta-gonads-mesonephros (AGM), to the placenta, to the fetal liver (FL) and, finally, to the whole bone marrow (WBM), ${ }^{2}$ the cell-surface phenotype of emerging HSCs also changes. The earliest specific cell-surface marker of the hematopoietic lineage in vivo, CD41, is expressed by HSC and hematopoietic progenitors in the E9 YS and E10.5-E11.5 AGM but is absent from E14.5 FL and WBM HSC. ${ }^{3-5}$ The pan-hematopoietic cell surface molecule, CD45, does not appear on HSCs until the late AGM and FL stages of development. ${ }^{6}$ In addition, in mice, CD34 is expressed by HSC throughout development beginning at the E9 YS stage but disappears from the most quiescent and primitive long-term WBM HSC several weeks after birth.3,7 Thus, the cell-surface phenotype of HSCs reflects their developmental maturity and origin.

HSCs are most rigorously defined by their ability to mediate the long-term reconstitution of the major peripheral blood (PB) compartments of primary and secondary recipients. Since the isolation of embryonic stem cells (ESCs) from murine blastocysts, researchers have attempted the derivation of transplantable HSCs. ${ }^{8-13}$ Our laboratory has reported the generation of engraftable HSCs from ESCs via ectopic expression of HoxB4 in embryoid body (EB)-derived cells followed by expansion on OP9 stroma. ${ }^{14}$ Before this, transplantation of undifferentiated ESC, unpurified EB-

Submitted December 9, 2008; accepted April 27, 2009. Prepublished online as Blood First Edition paper, May 6, 2009; DOI 10.1182/blood-2008-12-193888.

The online version of this article contains a data supplement. derived cells, or EB-derived cells transduced with oncogenes failed to result in significant hematopoietic repopulation. ${ }^{8-10}$ Although ESC-derived PgP-1/CD44 ${ }^{+} \mathrm{Lin}^{-}$cells were reported capable of long-term primary and secondary hematopoietic reconstitution, this finding was never replicated. ${ }^{11}$ Most recently, c-Kit ${ }^{+} \mathrm{CD} 45^{+} \mathrm{EB}-$ derived cells have been found to manifest long-term hematopoietic reconstitution in allogenic recipients and ameliorate the development of diabetes in nonobese diabetic mice. ${ }^{12,13}$ However, longterm reconstitution of secondary recipients via this system has not yet been demonstrated.

We have refined our HoxB4-based protocol and established a robust and reproducible system in which ESC-HSCs are engineered from murine ESCs. ${ }^{15}$ EB-derived cells subjected to a pulse of ectopic $C d x 4$ expression during EB differentiation are infected with retroviral HoxB4 and then expanded on OP9 stroma. We call the resulting heterogeneous population EPOCH cells (EB-derived, Passed on OP9s and treated with ectopic Cdx4 and HoxB4). These cells can rescue recipient animals from lethal irradiation, reconstitute the entire hematopoietic compartment of primary and secondary recipients long term, and generate functional lymphocytes in vivo. ${ }^{16-19}$ Retroviral marking demonstrates the presence of multilineage, self-renewing hematopoietic repopulating cells within the EPOCH cell population. ${ }^{15}$ However, because millions of EPOCH cells are necessary to rescue mice from lethal irradiation, ESCHSCs are either exceptionally rare within this pool of cells or are compromised in their capacity to engraft irradiated adult marrow. Thus, a thorough characterization of the cell-surface phenotype of the ESC-HSC, as has been done with in vivo HSC compartments, is 
crucial to their further study and characterization relative to the various stages of HSC development in the embryo and in bone marrow.

The authors of recent work ${ }^{20-23}$ have discovered that specific hematopoietic lineages derived from human ESCs bear the hallmarks of developmental immaturity: the attempted large-scale production of erythrocytes chiefly generates nucleated cells lacking adult globin gene expression. In addition, human ESC-derived lymphoid progenitor populations are $\mathrm{CD} 45^{\text {low }}$, indicative of developmental immaturity, and fail to generate $\mathrm{B}$ and $\mathrm{T}$ cells after in vitro coculture with OP9- $\delta$ stromal cells or fetal thymus, apparently attributable to a block in B- and T-cell development that biases toward natural killer-cell differentiation. ${ }^{24-26} \mathrm{CD} 34^{+}$cells isolated from 3- to 4-week-old human YS have demonstrated a similar differentiation bias. ${ }^{27}$ Thus, ESCs appear predisposed toward the production of developmentally immature hematopoietic populations. No data currently exist in mice or humans on the developmental status of ESC-HSCs. Because understanding the ontogeny of HSC development in the murine embryo will facilitate the directed differentiation of HSCs from ESCs, we have chosen to more thoroughly characterize the cell-surface phenotype of murine embryonic HSC populations. These experiments will also allow us to more stringently compare ESC-HSCs to all in vivo HSC compartments and place them within the hierarchy of HSC development.

\section{Methods}

\section{Cell culture and EPOCH cell generation}

$i C d x 4$ murine ESC and OP9 stromal cells (ATCC) were maintained as previously described. ${ }^{28} \mathrm{EPOCH}$ cell generation has been recently described in detail. ${ }^{29}$ In brief, $i C d x 4$ ESCs were differentiated in the presence of ascorbic acid, mono-thioglycerol, and holo-transferrin for 48 hours as hanging drops and then for an additional 4 days while shaking at $50 \mathrm{rpm}$. $C d x 4$ gene expression was induced via doxycycline from day 3 to day 6 of differentiation. At day 6, dissociated EBs were infected with MSCV-HoxB4internal ribosome entry site green fluorescent protein (IRES-GFP; multiplicity of infection 5-10) in 6-well plates preplated with OP9 stromal cells. After infection, cells were resuspended in Iscove modified Dulbecco medium (IMDM) supplemented with $10 \%$ fetal calf serum, $2 \mathrm{mmol} / \mathrm{L}$ penicillin/streptomycin/glutamine, $100 \mathrm{ng} / \mathrm{mL}$ human Flt3L, $100 \mathrm{ng} / \mathrm{mL}$ human stem cell factor, $40 \mathrm{ng} / \mathrm{mL}$ murine vascular endothelial growth factor, and $40 \mathrm{ng} / \mathrm{mL}$ human thrombopoietin, and then returned to their original OP9 preplated 6-well plates for 7 days. At day 7 of OP9 coculture, each plate was passaged into a $75-\mathrm{cm}^{2}$ tissue culture flask with fresh IMDM supplemented with serum and cytokines and cultured for an additional 3 to 5 days. All cytokines were obtained from Peprotech.

\section{Embryo dissections and cell preparations}

CD45.2 $2^{+}$C57BL/6 mice were used for timed matings. Approval was obtained from the institutional review board of Children's Hospital Boston for these studies. Embryonic day 0.5 (E0.5) equaled noon on the day of vaginal plug. Embryos were collected at E9 (15-20 somite pairs), E11.5, E12.5, and E14.5 for YS, AGM, placenta, and FL dissection, respectively. YS, AGM, and placenta were washed repeatedly with phosphate-buffered saline to minimize maternal blood contamination. YS was dissociated by incubation in $1 \mathrm{mg} / \mathrm{mL}$ collagenase/dispase (Sigma) in IMDM for 1 hour at $37^{\circ} \mathrm{C}$ with occasional trituration. AGM was dissociated by incubation in IMDM supplemented with $0.125 \%$ dispase (Invitrogen) for 30 to 45 minutes at $37^{\circ} \mathrm{C}$ with occasional trituration because preliminary studies revealed that this treatment best preserved the colony-forming unit (CFU) potential of $\mathrm{c}-\mathrm{Kit}^{+} \mathrm{CD} 34^{+} \mathrm{AGM}$ cells (see supplemental Figure 1, available on the Blood website; see the Supplemental Materials link at the top of the online article). Each individual placenta was drawn through an 18-gauge needle and incubated in IMDM plus $1 \mathrm{mg} / \mathrm{mL}$ collagenase/dispase (Sigma) for 1.5 hours at $37^{\circ} \mathrm{C}$ with occasional trituration. Placenta-derived cells were then overlaid on Ficoll (StemCell Technologies) and spun at $365 g$ for 20 minutes to remove excess debris. FLs were dispersed via mashing on a 70-micron filter.

\section{Cell fractionation}

All cells were fractionated by either magnetic beads or fluorescenceactivated cell sorting (FACS). For FACS, a triple-LASER instrument (FACSAria; BD Biosciences) was used, and 7-aminoactinomycin D or 4',6diamidino-2-phenylindole (Sigma) was used to exclude dead cells. For magnetic bead selection, antiphycoerythrin microbeads (Miltenyi Biotec) and LS columns (Miltenyi Biotec) were used according to the manufacturer's instructions. The following antibodies were used for fractionation: CD41 (MWReg-30), CD48 (HM48-1, Biolegend), CD48 (OX78, Abcam), CD150 (TC15-12F12.2, Biolegend), CD34 (RAM34), c-Kit (2B8), and CD45 (30-F11). Unless otherwise indicated, all antibodies were obtained from BD Biosciences.

\section{Transplants}

For EPOCH cell transplants, C57BL/6 Rag- $2^{-1-} \mathrm{yc}^{-1-}$ mice weighing less than $22 \mathrm{~g}$ were given 2 doses of $4.6 \mathrm{~Gy}$ of irradiation, separated by 2.5 hours, and transplanted via the lateral tail vein. For embryonic cell transplants, CD45.1 ${ }^{+}$C57BL/6 mice were given 2 doses of $5.5 \mathrm{~Gy}$ of irradiation, separated by 2.5 hours, and transplanted with $2.5 \times 10^{5} \mathrm{CD} 45.1^{+}$/ CD $45.2^{+}$WBM cells plus CD $45.2^{+}$embryonic cells via retro-orbital injection. PB of recipients was analyzed every 4 weeks by FACS for engraftment using the following antibodies: CD45.1 (A20), CD45.2, (104) CD3 (145-2C11), CD4 (GK1.5), CD8 (536.7), CD19 (1D3), B220 (RA36B2), IgM (11/41), Gr-1 (RB6-8C5), and Mac-1 (M1/70).

\section{Results}

\section{CD150 is developmentally regulated on the cell surface of HSCs}

Although HSCs have recently been prospectively isolated from FL and WBM based on the signaling lymphocyte activation molecule (SLAM) markers CD48 and CD150, the expression of these molecules has not been evaluated during HSC ontogeny. ${ }^{30,31}$ Thus, we dissected AGM from E11.5 embryos (Figure 1A) and analyzed CD48 and CD150 expression by FACS. Few AGM cells expressed CD150 (0.24\%; Figure 1B), whereas a larger percentage of CD48 ${ }^{+}$ cells was apparent $(2 \%$; Figure $1 \mathrm{~B})$. Interestingly, the CD150+ AGM cells appeared enriched for CD41 ${ }^{\text {high }}$ cells relative to the CD $48^{+}$AGM compartment (Figure 1B). To assess which compartments possessed HSC activity, we transplanted AGM-derived cells fractionated based on CD150 and CD48 expression along with competitor WBM into lethally irradiated recipients, taking advantage of allelic differences in CD45 such that all sources of repopulation in recipient animals could be discerned (Figure 1C; Table 1). Whereas 3 of 8 mice transplanted with $\mathrm{CD} 150^{-} \mathrm{CD} 48^{-}$ AGM cells showed long-term multilineage AGM-derived PB reconstitution (Figure 1D; Table 1), no mice transplanted with $\mathrm{CD} 48^{+}$or $\mathrm{CD} 150^{+}$cells ever displayed evidence of AGM engraftment (Table 1), indicating that the double-negative fraction contains AGM HSC activity. Importantly, CD $150^{-} \mathrm{CD} 48^{-} \mathrm{AGM}$ cells were also capable of reconstituting the hematopoietic compartment of secondary recipients (see supplemental Figure 2). We further fractionated the $\mathrm{CD} 150^{-} \mathrm{CD} 48^{-} \mathrm{AGM}$ cells for CD41 expression and found HSC activity in both the CD41- and CD41 ${ }^{+}$compartments (see supplemental Figure 3; Table 1). These data suggest that 


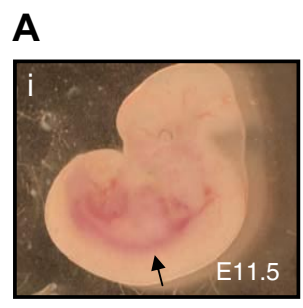

B
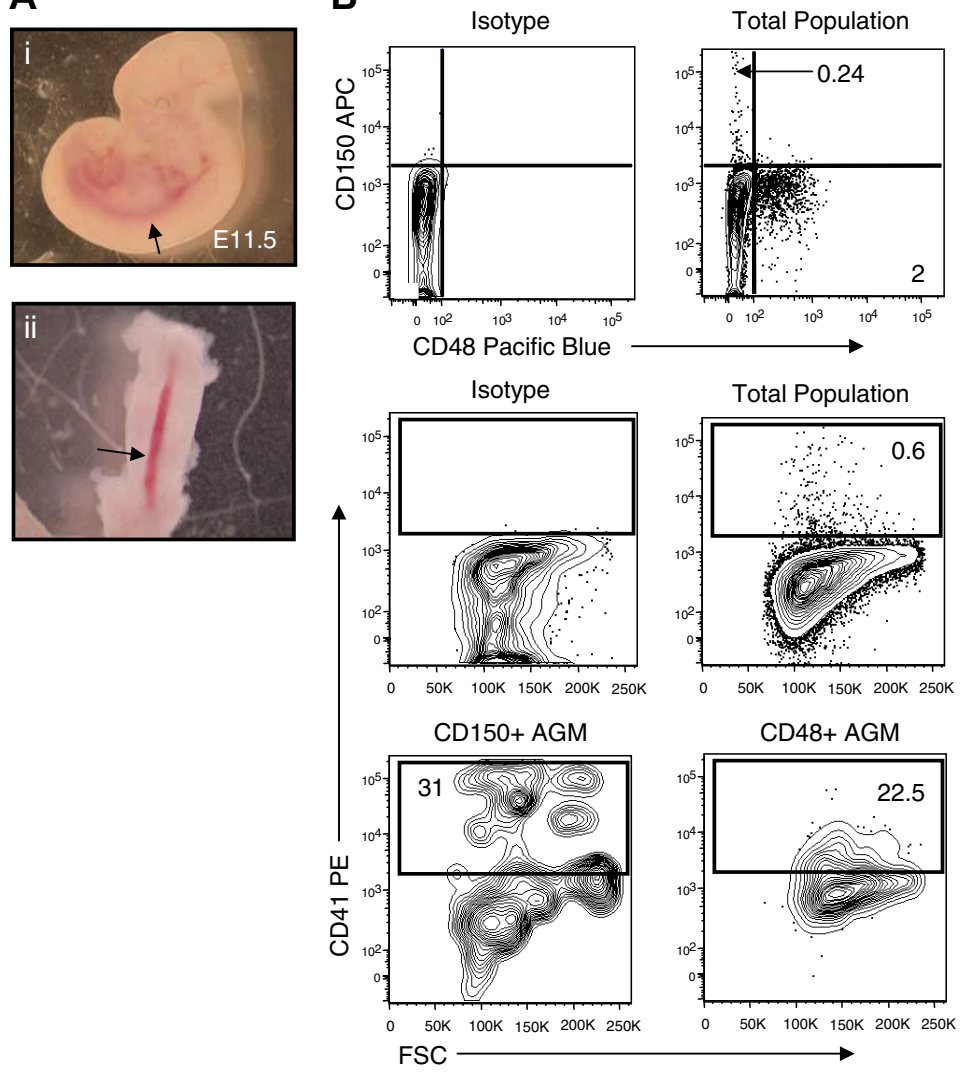

Total Population

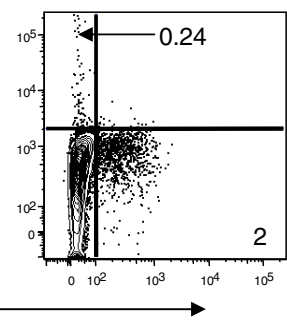

Total Population

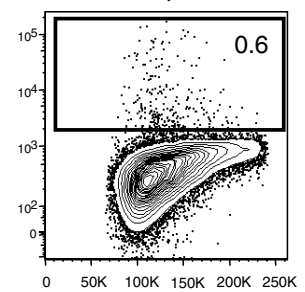

D

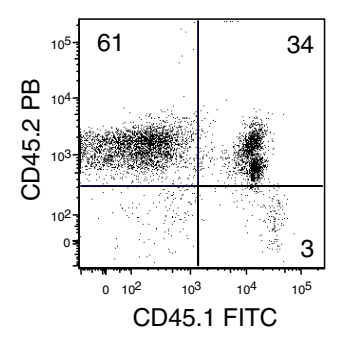

45.2 PB

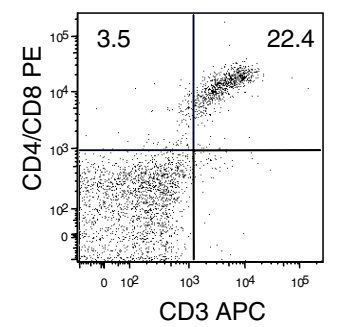

E11.5 AGM

E12.5 Placenta E14.5 Fetal Liver WBM

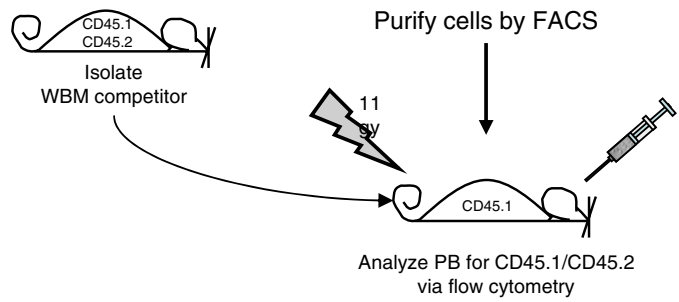

7 months after transplant

45.2 PB
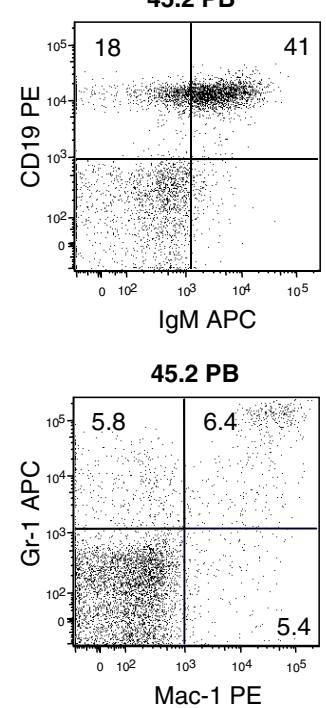

Figure 1. E11.5 AGM-derived repopulating cells do not express CD150 or CD48. (A) E11.5 embryos before (i) and after (ii) AGM dissection. The image was captured at room temperature by the use of a Leica MZ16 scope and a Nikon COOLPIX camera. Total magnification $\times 400$. Arrows denote the aorta. (B) Flow cytometry analysis of CD48, CD150, and CD41 expression on AGM cells. (C) To assess the in vivo hematopoietic repopulating potential of cells isolated from E11.5 AGM, E12.5 placenta, E14.5 FL, and WBM, donor cells from each tissue were isolated from CD45.2 C57BL/6 mice, fractionated via FACS, and then transplanted into irradiated CD45.1 C57BL/6 mice along with $2.5 \times 10^{5}$ competitor WBM cells isolated from CD45.1/CD45.2 C57BL/6 mice. Recipient PB mice were then analyzed every 4 weeks for the presence of CD45.2 ${ }^{+}$(ie,

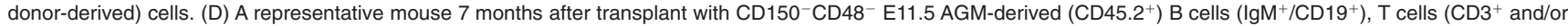
$\left.\mathrm{CD}^{+} / \mathrm{CD} 8^{+}\right)$, and myeloid cells $\left(\mathrm{Gr}-1^{+}\right.$and/or $\left.\mathrm{Mac}-1^{+}\right)$.

AGM HSCs lose CD41 expression at this stage of development. AGM cells purified with an alternate anti-CD48 antibody clone, OX78, still failed to chimerize recipient animals (Table 1). Thus, unlike their WBM and FL counterparts, AGM HSCs are CD $150^{-} \mathrm{CD}^{-} 8^{-}$.

We next evaluated E12.5 placental HSCs for CD150 and CD48 expression (Figure 2A). The placenta harbors a large pool of c-Kit ${ }^{+} \mathrm{CD} 34{ }^{\mathrm{med}} \mathrm{HSCs}$ that peak in frequency at E12.5. ${ }^{32} \mathrm{We}$ found c-Kit ${ }^{+} \mathrm{CD} 34^{\text {med }}$ placental cells heterogeneous with respect to CD48 expression (Figure 2B). The repopulating potential of placental HSCs with respect to CD48 expression was assessed via fractionation by FACS and transplantation into lethally irradiated mice (Figure 1C; supplemental Figure 4A; Table 2). In 4 independent experiments, none of 18 mice transplanted with $\mathrm{CD} 48^{+}$cells ever displayed placenta-derived engraftment (Table 2). In contrast, 9 of 10 mice transplanted with CD48- cells displayed long-term multilineage engraftment (Figure 2C; Table 2). We also fractionated placental cells by using the anti-CD48 antibody clone, OX78, and again found engraftment only in mice transplanted with $\mathrm{CD} 48^{-}$ cells (Table 2). These data argue strongly that placental HSC at
E12.5 lack CD48. Interestingly, both the CD41 ${ }^{+}$and CD41compartment of $\mathrm{CD} 48^{-}$placenta cells engrafted recipient mice, suggesting that E12.5 placental HSCs, like AGM HSCs, were heterogeneous with respect to CD41 expression (Figure 2D; see supplemental Figure 4B; Table 2).

We next examined whether placental HSCs express CD150. In 2 independent experiments, none of 4 animals transplanted with $\mathrm{CD} 150^{+}$placenta cells engrafted (Figure 2E; supplemental Figure $4 \mathrm{C}$; Table 2). In contrast, 8 of 8 recipients of CD150- placenta cells were highly engrafted in the PB more than 14 weeks after transplant (Figure 2F; Table 2). These data demonstrate that E12.5 placental HSCs, like AGM HSCs, do not express CD150.

We also examined E9 YS for the expression of CD150 and CD48. $\mathrm{CD} 41^{\text {high }} \mathrm{C}-\mathrm{Kit}^{+} \mathrm{CD} 34^{+}$cells present in the E9 YS can support the lifelong reconstitution of the hematopoietic compartment when transplanted into the neonatal liver. ${ }^{3}$ YSs were dissected from E9 embryos (15-20 somite pairs), dissociated into a single-cell suspension by treatment with collagenase/dispase, and then analyzed by flow cytometry for the coexpression of CD41, c-Kit, CD34, CD150, and CD48. In multiple independent analyses, we failed to detect CD48 or CD150 
From bloodjournal.hematologylibrary.org at ECOLE POLYTECHNIQUE FEDERALE DE LAUSANNE on March 25, 2014. For personal use only.

BLOOD, 9 JULY $2009 \cdot$ VOLUME 114, NUMBER 2

Table 1. E11.5 AGM-derived long-term repopulating cells are CD150-CD48-

\begin{tabular}{|c|c|c|c|c|c|c|}
\hline AGM cell population & $\%$ of population & $\begin{array}{l}\text { Experimental } \\
\text { enrichment }\end{array}$ & $\begin{array}{c}\text { No. of embryo } \\
\text { equivalents transplanted }\end{array}$ & $\begin{array}{c}\text { No. of AGM } \\
\text { cells transplanted, } \times 10^{4}\end{array}$ & $\begin{array}{l}\text { No. reconstituted/no. } \\
\text { transplanted }\end{array}$ & $\begin{array}{l}\% \text { of long-term } \\
\text { reconstitution } † \ddagger\end{array}$ \\
\hline $\mathrm{CD} 150^{+} \mathrm{CD} 48^{+} \S$ & 0.03 & nd & 1 & 0.08 & $0 / 1$ & \\
\hline CD150-CD48+ & $0.9-1.6$ & $50-109$ & $1.5-2$ & $0.4-0.8$ & $0 / 14$ & \\
\hline CD150+CD48 ${ }^{-} \|$ & $0.1-0.8$ & $38-115$ & $1-2$ & $0.05-0.5$ & $0 / 3$ & \\
\hline CD150-CD48-9 & $97-98$ & 1 & $1-2$ & 26-41 & $3 / 8$ & $0.8-26$ \\
\hline 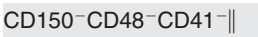 & $95-96$ & 1 & $1.5-2$ & $39-42$ & $2 / 6$ & $21-63$ \\
\hline CD150-CD48-CD41 ${ }^{+* *}$ & $0.7-0.6$ & $120-140$ & $1-3.3$ & $0.16-0.32$ & $4 / 4$ & $1.7-51$ \\
\hline $\mathrm{CD} 150+\mathrm{CD}^{2} 8^{-} \mathrm{CD} 41^{+} \S$ & 0.34 & 272 & 1.1 & 0.040 & $0 / 2$ & \\
\hline $\mathrm{CD} 150^{-} \mathrm{CD} 48^{+} \mathrm{CD} 41^{+} \S$ & 0.1 & 650 & 5.6 & 0.2 & $0 / 6$ & \\
\hline $\mathrm{CD} 48^{+}(\mathrm{O} \times 78) \S$ & 1.6 & 60 & 2 & 1 & $0 / 1$ & \\
\hline $\mathrm{CD} 48^{-}(\mathrm{OX} 78) \S$ & 97 & 1 & 2 & 63 & $3 / 3$ & $0.8-43 \dagger \dagger$ \\
\hline
\end{tabular}

*Experimental enrichment is calculated by dividing the frequency of the population after sort by the frequency of the population before sort.

†Reconstitution is defined as the presence of AGM-derived cells in both the myeloid and lymphoid compartments of the peripheral blood of mice undergoing transplantation.

†Reconstitution presented is based on the frequency of AGM-derived cells in the peripheral blood of mice undergoing transplantation at 17-24 weeks after transplantation. $\S$ Data from 1 experiment.

IPooling of data from 4 independent experiments.

|Pooling of data from 2 independent experiments.

** Pooling of data from 3 independent experiments.

††Eight weeks after transplantation.

expression on either $\mathrm{CD} 41^{+} \mathrm{c}-\mathrm{Kit}^{+} \mathrm{CD} 34^{+}$or total YS cells (Figure 3). Thus, it appears likely that definitive HSCs present in the E9 YS lack CD150 and CD48 expression.

Importantly, to verify that our failure to observe repopulating activity in the CD $150^{+}$compartment of AGM and placenta was not caused by a technical inability to fractionate CD150 ${ }^{+} \mathrm{HSC}$, we purified $\mathrm{CD} 150^{+}$cells from FL and WBM and documented robust reconstitution in recipient mice (see supplemental Figure 5).

In summary, our data demonstrate that CD150 is developmentally regulated on the surface of HSCs: it is absent from repopulating cells in the E9 YS, E11.5 AGM, and E12.5 placenta but present in the E14.5 FL and WBM. In contrast, CD48 is never expressed on fetal or adult HSCs.

\section{ESC-HSCs are CD41 ${ }^{\text {high }}$ CD $34-$ but heterogeneous with respect to CD45 expression}

We next turned our attention to the characterization of the cell-surface phenotype of murine ESC-HSCs derived by our EPOCH protocol. To generate EPOCH cells, $i C d x 4$ ESC were exposed to doxycycline from day 3 to day 6 of EB differentiation, infected with MSCV-HoxB4-IRES-GFP, and then expanded on OP9 stroma in the presence of hematopoietic cytokines stem cell factor, human Flt3 ligand, vascular endothelial growth factor, and thyroid thrombopoietin for 10 days (Figure 4A). On average, 100000 EB-derived cells plated on OP9 stroma at day 0 generated $68( \pm 19 \%)$ hematopoietic colonies at day 7 of expansion and ultimately resulted in $6.9 \times 10^{6} \pm 2.3 \times 10^{6} \mathrm{EPOCH}$ cells by day 10 (see supplemental Figure 6A). These data suggest that OP9 colony-initiating cells are rare within the EB because only approximately 1 in 1500 EB-derived cells responds to HoxB4 infection by robust expansion on $\mathrm{OP} 9$ stroma. We determined experimentally that a minimum of $2-5 \times 10^{6} \mathrm{EPOCH}$ cells are required to rescue Rag- $2^{-1-} \gamma \mathrm{c}^{-1-}$ mice from lethal irradiation (see supplemental Figure 6B), indicating that the frequency of ESC-HSC within this population is extremely rare.

Although EPOCH cells are highly enriched for CFUs relative to WBM (see supplemental Figure 6C), we found that EPOCH cells are not nearly as robust as WBM at rescuing mice from irradiation. Although $2.5 \times 10^{5} \mathrm{WBM}$ cells could rescue mice from up to 10.5 Gy of irradiation, $2 \times 10^{6} \mathrm{EPOCH}$ cells could only rescue the
Figure 2. E12.5 Placenta-derived repopulating cells do not express CD150 or CD48. (A) E12.5 embryo after dissection of placenta. $P$ indicates placenta; $Y S$, yolk sac; and $\mathrm{E}$, embryo. The image was captured at room temperature by the use of a Leica MZ16 scope and a Nikon COOLPIX camera. Total approximate magnification $\times 12$. (B) Flow cytometry analysis of E12.5 placenta for CD34, C-Kit, and CD48 expression. Because the placenta contains a large population of autofluorescent cells that make resolution of the c-Kit ${ }^{+} \mathrm{CD} 34^{\text {med }}$ compartment difficult, we also dissociated E12.5 FL and used it as a guide to gate $\mathrm{C}-\mathrm{Kit}^{+} \mathrm{CD} 34^{\mathrm{med}}$ placenta cells $(\mathrm{H}$. Mikkola, personal written communication, October 2009). (C) A representative mouse 19 weeks after transplantation with $\mathrm{CD} 34^{\text {med }} \mathrm{C}^{-} \mathrm{Kit}^{+} \mathrm{CD} 48^{-} \mathrm{E} 12.5$ placentaderived $\left(\mathrm{CD} 45.2^{+}\right) \mathrm{B}$ cells $\left(\mathrm{IgM}^{+} / \mathrm{CD} 19^{+}\right)$, $\mathrm{T}$ cells $\left(\mathrm{CD}^{+}\right.$and/or $\left.\mathrm{CD}^{+} / \mathrm{CD}^{+}\right)$, and myeloid cells $\left(\mathrm{Gr}-1^{+}\right.$and/or Mac- $\left.1^{+}\right)$. (D) Flow cytometry analysis of CD48 and CD41 expression on E12.5 placenta cells. (E) Flow cytometry analysis of CD150 expression on E12.5 placenta cells. (F) A representative mouse 19 weeks after transplantation with $\mathrm{CD} 150^{-} \mathrm{E} 12.5$ placenta-derived $\left(\mathrm{CD} 45.2^{+}\right) \mathrm{B}$ cells $\left(\mathrm{IgM}^{+} / \mathrm{CD} 19^{+}\right), \mathrm{T}$ cells $\left(\mathrm{CD}^{+}\right.$and/or $\left.\mathrm{CD} 4^{+} / \mathrm{CD}^{+}\right)$, and myeloid cells $\left(\mathrm{Gr}-1^{+}\right.$and/or Mac- $\left.{ }^{+}\right)$.
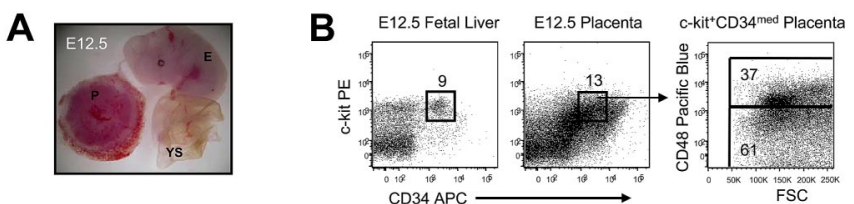

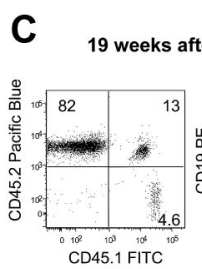

D
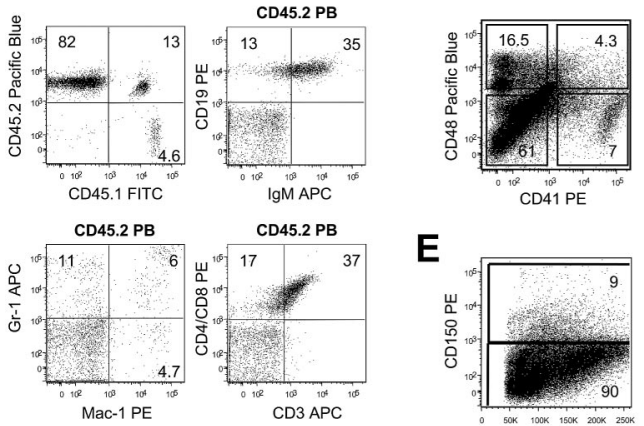

E
$\mathbf{F}$
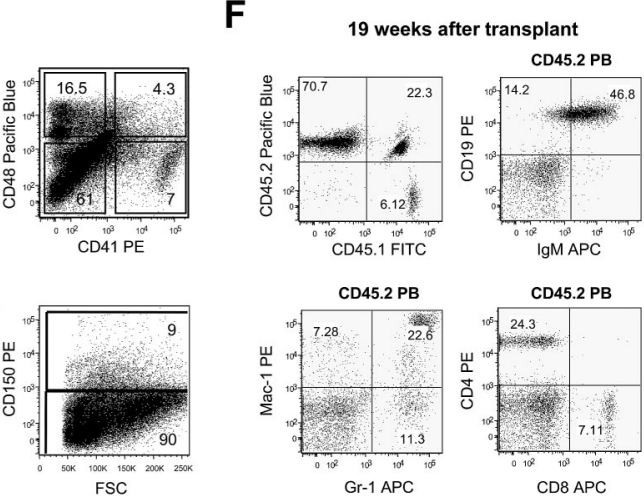
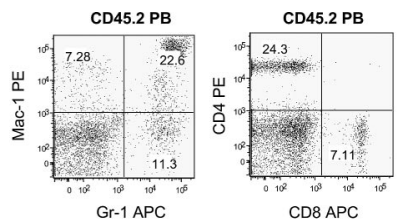
From bloodjournal.hematologylibrary.org at ECOLE POLYTECHNIQUE FEDERALE DE LAUSANNE on March 25, 2014. For personal use only.

Table 2. E12.5 Placenta-derived long-term repopulating cells are CD150-CD48-

\begin{tabular}{|c|c|c|c|c|c|c|}
\hline $\begin{array}{l}\text { Placenta cell } \\
\text { population }\end{array}$ & $\%$ of population & $\begin{array}{l}\text { Experimental } \\
\text { Enrichment* }\end{array}$ & $\begin{array}{c}\text { Number of embryo } \\
\text { equivalents } \\
\text { transplanted }\end{array}$ & $\begin{array}{l}\text { Number of placenta cells } \\
\text { transplanted, } \times 10^{3}\end{array}$ & $\begin{array}{c}\text { Number of } \\
\text { reconstituted/transplanted }\end{array}$ & $\begin{array}{l}\% \text { reconstitution } \\
\text { long-term†‡ }\end{array}$ \\
\hline $\mathrm{c}-\mathrm{Kit}^{+} \mathrm{CD} 48^{-} \S$ & 12 & 8 & 0.5 & 31.5 & $1 / 1$ & 86 \\
\hline $\mathrm{c}-\mathrm{Kit}^{+} \mathrm{CD} 48^{+} \S$ & 8 & 12 & 0.5 & 22.3 & $0 / 5$ & \\
\hline 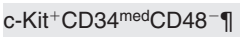 & $1.5-9$ & $11-69$ & $0.2-0.75$ & $3.2-46.5$ & $7 / 8$ & $0.75-90$ \\
\hline $\mathrm{c}-\mathrm{Kit}^{+} \mathrm{CD} 34^{\mathrm{med}} \mathrm{CD} 48^{+}$ & $1.7-4.6$ & $21-54$ & $0.2-1$ & $4.6-14$ & $0 / 18$ & \\
\hline $\mathrm{CD}_{4} 8^{-} \S$ & 72 & 1.4 & 0.5 & 115 & $1 / 1$ & 93 \\
\hline $\mathrm{CD}_{4} 8^{+} \S$ & 24 & 4 & 0.75 & 36.8 & $0 / 2$ & \\
\hline $\mathrm{CD} 41^{-} \mathrm{CD} 48^{-} \S$ & 58 & 1.7 & 3 & 150 & $3 / 3$ & $73-91$ \\
\hline $\mathrm{CD} 41^{+} \mathrm{CD}_{4} 8^{-} \S$ & 6.7 & 11.5 & 7.5 & 45 & $2 / 3$ & $70-83 \|$ \\
\hline $\mathrm{CD} 41^{-} \mathrm{CD} 48^{+} \S$ & 18 & 5.4 & 2.75 & 47 & $0 / 4$ & \\
\hline $\mathrm{CD} 41^{+} \mathrm{CD} 48^{+} \S$ & 1.5 & 66 & 4 & 4.3 & $0 / 4$ & \\
\hline $\mathrm{CD}^{-} 8^{-}(\mathrm{OX78}) \S$ & 92 & 1 & 1 & 168 & $3 / 3$ & $71-78^{\star \star}$ \\
\hline $\mathrm{CD}_{48}^{+}(\mathrm{OX78}) \S$ & 3.2 & 31 & 1 & 25 & $0 / 2$ & \\
\hline CD150-†† & $88-92$ & $1-1.2$ & $0.5-0.9$ & $4.4-10$ & $8 / 8$ & $40-86$ \\
\hline CD150+†† & $7-7.6$ & $11.5-13.9$ & $0.5-0.7$ & $150-870$ & $0 / 4$ & \\
\hline
\end{tabular}

*Experimental enrichment is calculated by dividing the frequency of the population after sort by the frequency of the population before sort.

†Reconstitution is defined as the presence of placenta-derived cells in both the myeloid and lymphoid compartments of the PB of transplanted mice.

†Reconstitution presented is based on the frequency of placenta-derived cells in the peripheral blood of mice undergoing transplantation at $19-27$ weeks after transplantation.

$\S$ Data of 1 experiment.

IPooling of data from 4 independent experiments.

$\|$ Because of contamination of CD41- cells in the $\mathrm{CD} 41^{+} \mathrm{CD} 48^{-}$population, cannot rule out possibility that $\mathrm{CD} 41^{+} \mathrm{CD} 48^{-}$engraftment is $\mathrm{CD} 41^{-}$derived.

**Eight weeks after transplant.

††Pooling of data from 2 independent experiments.

majority of mice up to $9.25 \mathrm{~Gy}$ of irradiation (see supplemental Figure 6D). Given that these doses of EPOCH cells or WBM have similar numbers of CFU-S 12 (see supplemental Figure 6E), these data suggest inherent functional differences in the nature of the hematopoietic progenitors in EPOCH cells versus WBM. Indeed, preliminary work revealed that even an excess of EPOCH cells mediate only transient hematopoietic engraftment when transplanted along with WBM competitor (data not shown). Thus, all transplants of EPOCH described in this article are performed in the absence of competitor WBM. Despite these functional differences, EPOCH cells transplanted in the absence of competitor, under our optimal conditions, routinely yield long-term, multilineage engraftment of recipient mice (see supplemental Figure 6E).

The significant differences in the reconstituting ability of ESC-derived EPOCH cells compared with WBM-derived HSC prompted us to hypothesize that ESC-HSCs might resemble an embryonic HSC compartment rather than adult bone marrow HSCs. EPOCH cells are heterogeneous with respect to cell-surface phenotype (Figure 4B). In a representative experiment, $80 \%$ and $39 \%$ of EPOCH cells expressed CD41 and CD45, respectively (Figure 5A). EPOCH cells were fractionated on the basis of the expression of these 2 molecules by magnetic bead selection to high purity and transplanted into irradiated $\mathrm{Rag}-2^{-1-} \gamma \mathrm{c}^{-/-}$recipients at the indicated cell doses (see supplemental Figure 7A; Table 3). Strikingly, in 2 independent experiments, all recipients of CD41EPOCH cells perished by 20 days after transplant, whereas all $\mathrm{CD}_{4} 1^{+}$recipients were rescued for more than 90 days after transplant (Figure 5B), 4 of whom displayed multilineage engraftment for more than 26 weeks after transplant (Table 3; Figure 5C). Surprisingly, 5 of 6 and 6 of 6 recipients of CD45 $5^{+}$and CD45 EPOCH cells, respectively, also were rescued from lethal irradiation for at least 90 days after transplant (Table 3; Figure 5B). Survivors from each cohort also displayed multilineage engraftment for more than 26 weeks after transplant (Table 3; Figure 5C). In agreement with our in vivo engraftment studies, $\mathrm{CD} 41^{-} \mathrm{EPOCH}$ cells yielded far fewer CFUs than $\mathrm{CD} 41^{+} \mathrm{EPOCH}$ cells, whereas both $\mathrm{CD} 45^{+}$and $\mathrm{CD} 45^{-} \mathrm{EPOCH}$
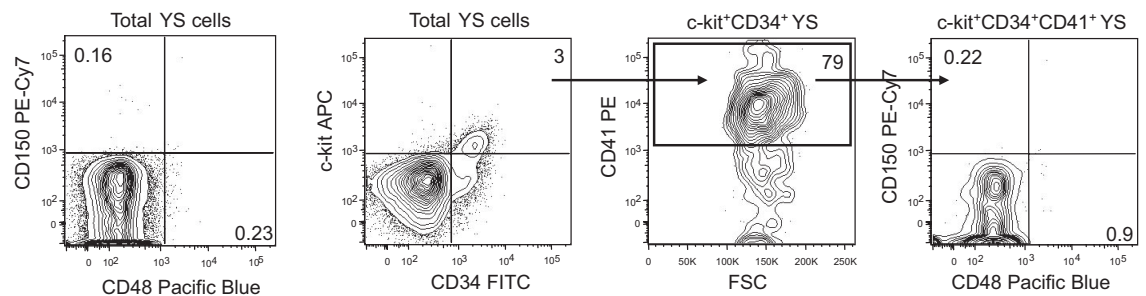

Isotype Controls
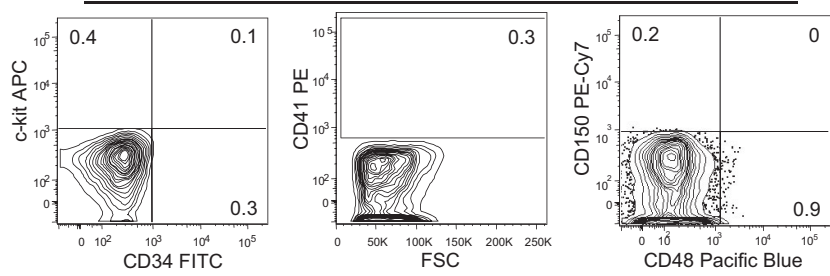

Figure 3. CD150 and CD48 expressing cells are not detectable in E9 YS. Representative analysis of E9 YS-derived cells analyzed by flow cytometry for the cell surface expression of c-Kit, CD34, CD41, CD150, and CD48. Isotype controls for each antibody are also shown. 


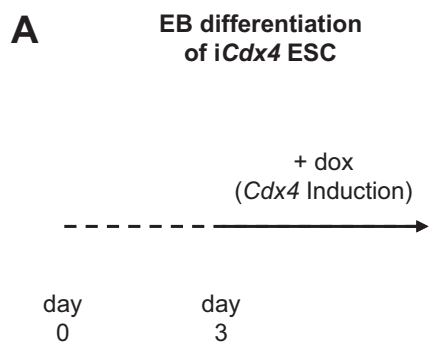

B

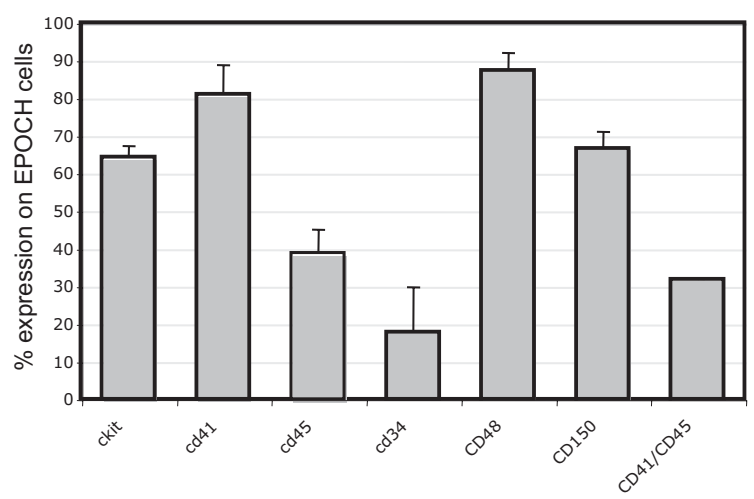

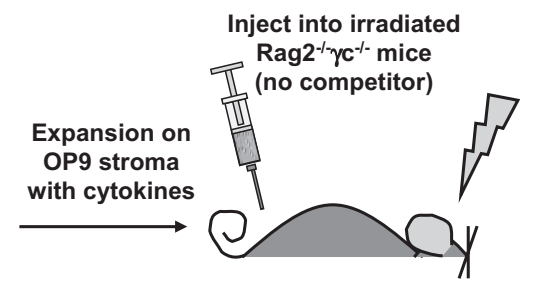

day

16

C

Figure 4. EPOCH cells are phenotypically heterogeneous. (A) To generate EPOCH cells, iCdx4 ESC differentiated in the presence of doxycycline (day 3 to day 6 of differentiation) were infected with retroviral MSCV-HoxB4-IRES-GFP and expanded on OP9 stroma with cytokines for 10 days before transplantation into irradiated Rag- $2^{-/-} \gamma \mathrm{c}^{-/-}$mice. (B) EPOCH cells expanded on OP9 stroma for 10 days were analyzed by flow cytometry for the expression of cell surface markers previously shown to be relevant to HSC biology (c-Kit, CD41, CD45, CD34, CD48, and CD150). Data presented are the summary of at least 3 independent experiments. (C) CD41, CD45, and C-Kit expression on surface of EPOCH cells is shown.

cells contained significant CFU activity (see supplemental Figure 8A). These data reveal that although ESC-HSCs uniformly express CD41, they are heterogeneous with respect to CD45 expression.

Coexpression analysis of CD45 and CD41 on EPOCH cells reveals, as our transplantation data would predict, that the $\mathrm{CD} 41^{+}$ EPOCH cell compartment is heterogeneous with respect to CD45 (Figure 5D). Interestingly, c-Kit expression segregates with the $\mathrm{CD} 41^{+}$cells expressing the highest levels of CD41 (Figure 4C). Previous studies ${ }^{3}$ have shown that the most definitive hematopoietic progenitors during development express high levels of CD41, whereas primitive hematopoietic progenitors are $\mathrm{CD} 41^{\text {low }}$. To determine whether ESC-HSCs could be restricted to the CD41 high EPOCH cell compartment, we performed 2 independent experiments in which $\mathrm{CD} 45^{-} \mathrm{CD} 41^{\text {low }}, \mathrm{CD} 45^{-} \mathrm{CD} 41^{\text {high }}, \mathrm{CD} 45^{+} \mathrm{CD} 41^{\text {low }}$, and $\mathrm{CD} 45^{+} \mathrm{CD} 41^{\text {high }} \mathrm{EPOCH}$ cells were transplanted into Rag-2 ${ }^{-/}$ $-\gamma \mathrm{c}^{-1-}$ recipients (see supplemental Figure 7B). All 12 recipients of $\mathrm{CD} 41^{\text {low }} \mathrm{EPOCH}$ cells succumbed to lethal irradiation by 25 days after transplant, whereas 8 of 12 recipients of CD41 high cells were rescued (Figure 5E; Table 3).

Although recipients of both $\mathrm{CD} 45^{-} \mathrm{CD} 41^{\text {high }}$ and $\mathrm{CD} 45^{+} \mathrm{CD} 41^{\text {high }}$ maintained engraftment out to at least 22 weeks after transplant, the recipients of $\mathrm{CD} 45^{-} \mathrm{CD} 41^{\text {high }}$ cells appeared to maintain a greater level of long-term engraftment (Figure 5F). In addition, in one experiment, $\mathrm{CD} 45^{-} \mathrm{CD} 41^{\text {high }} \mathrm{EPOCH}$ cells were enriched for CFU-GEMM activity relative to $\mathrm{CD} 45^{+} \mathrm{CD} 41^{\text {high }}$ cells (see supplemental Figure 8B). Interestingly, EPOCH cells expressing the greatest levels of c-Kit either lack CD45 or express only moderate levels of this molecule (Figure 4C). C-Kit is expressed by HSC throughout development, whereas CD45 expression levels have been linked to developmental immaturity. ${ }^{33,34}$ In summary, these data reveal that ESC-HSCs express high levels of CD41 and although heterogeneous with respect to CD45 expression, the most potent long-term ESC-HSCs express only moderate levels of this molecule.

To further refine the cell-surface phenotype of ESC-HSCs, we examined the coexpression of CD41 and CD34 on EPOCH cells. CD41 ${ }^{+}$EPOCH cells are heterogeneous for CD34 expression (Figure 5G). EPOCH cells were fractionated by FACS based on the expression of CD34 alone or both CD41 and CD34 and transplanted into $\mathrm{Rag}-2^{-/-} \gamma \mathrm{c}^{-/-}$recipient mice (see supplemental Figure 7C). All 10 recipients of $\mathrm{CD} 34^{+} \mathrm{EPOCH}$ cells perished by 20 days after transplantation, whereas 8 of 9 recipients of CD34 ${ }^{-}$ EPOCH cells were rescued for at least 90 days after transplant (Figure 5H; Table 3). All recipients of $\mathrm{CD} 41^{+} \mathrm{CD} 34^{-} \mathrm{EPOCH}$ cells maintained high-level EPOCH cell-derived $\mathrm{PB}$ chimerism at 18 weeks after transplant (Figure 5I). Thus, ESC-HSCs do not express CD34. The phenotypic analyses presented thus far reveal that murine ESC-HSCs are restricted to the $\mathrm{CD} 41^{\text {high }} \mathrm{CD} 34^{-}$ fraction of EPOCH cells but that this cell compartment is heterogeneous with respect to CD45 expression, with the most potent ESC-HSCs expressing intermediate levels of CD45.

\section{ESC-HSCs are CD150+ but heterogeneous with respect to CD48 cell-surface expression}

High CD41 and moderate CD45 expression reveals that ESC-HSCs phenotypically resemble developmentally immature HSCs. Given our data that CD150, like CD41 and CD45, is developmentally regulated on HSCs, we next evaluated the expression of the SLAM family members, CD150 and CD48, on the surface of EPOCH cell-derived ESC-HSCs.

EPOCH cells were fractionated by magnetic selection into $\mathrm{CD} 48^{+}$and $\mathrm{CD} 48^{-}$subsets and transplanted into Rag- $2^{-1-} \gamma \mathrm{c}^{-/-}$ recipient mice (Figure 6A). In 2 independent experiments, 2 of 
A

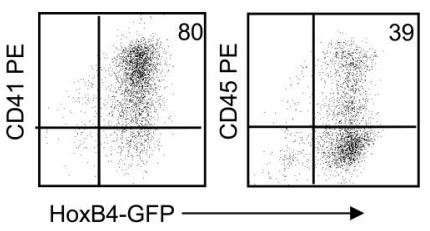

D

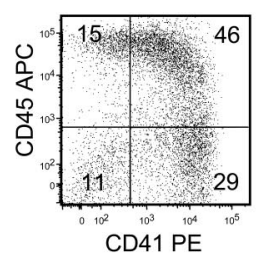

E

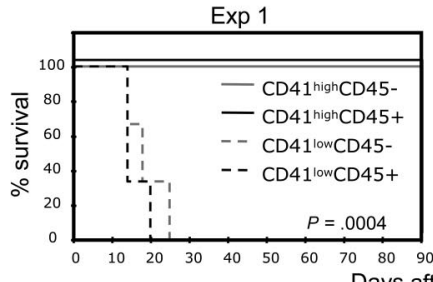

Days after transplant

$\mathbf{F}$

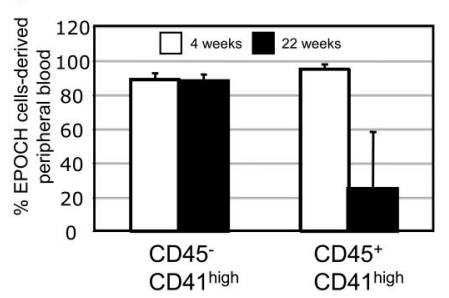

B

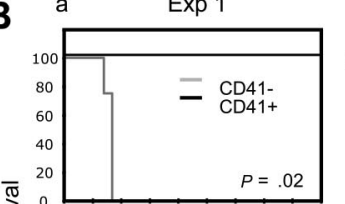

弯

$P=.02$

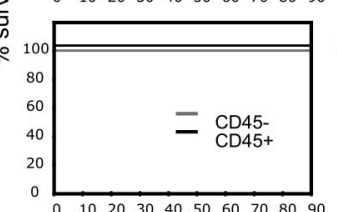

Days after transplant
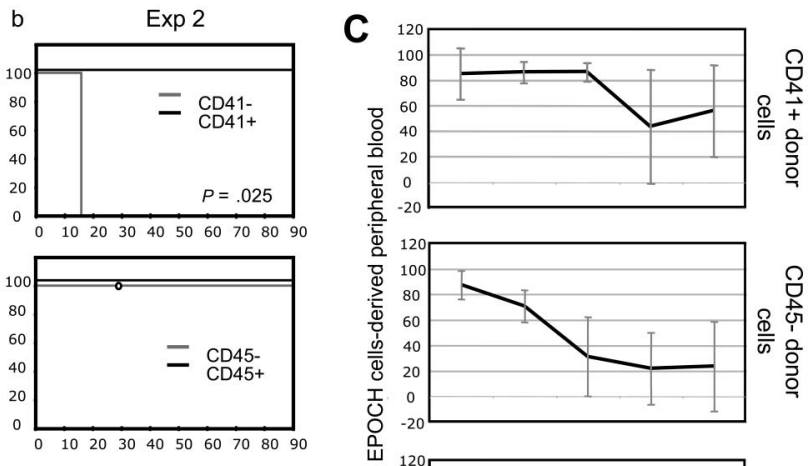

ㅇ 100

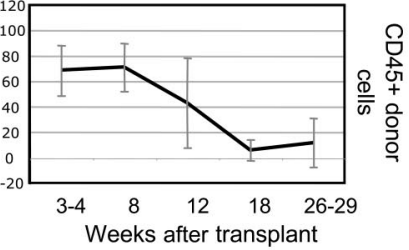

1

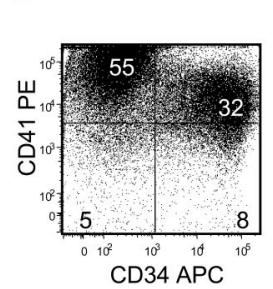

H

- CD41 $1^{\text {high }} \mathrm{CD} 45-$

- $\mathrm{CD} 41^{\text {high }} \mathrm{CD} 45+$

- - CD41lowCD45-
- - CD41lowCD45+
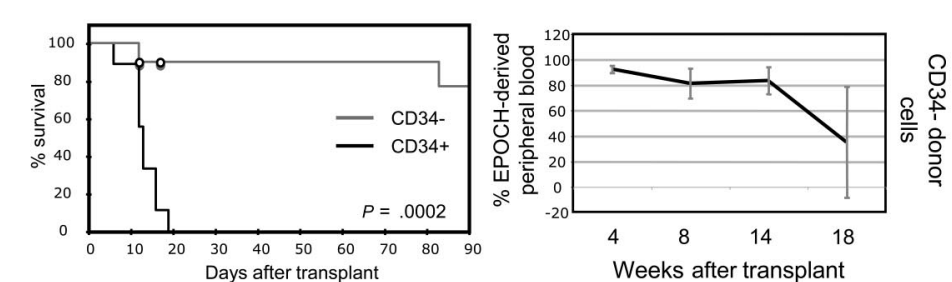

Figure 5. ESC-HSC are CD41 high CD34- and heterogeneous with respect to CD45 cell-surface expression. (A) CD41 and CD45 expression on EPOCH cells is shown. (B) Kaplan-Meier survival analyses and (C) EPOCH cell-derived PB reconstitution of Rag- $2^{-1-} \gamma \mathrm{c}^{-1-}$ mice transplanted with EPOCH cells fractionated for CD41 or CD45 expression. EPOCH cell-derived PB is GFP ${ }^{+}$. Two independent experiments are presented. (D) CD45 and CD41 coexpression on EPOCH cells are shown. (E) Shown are Kaplan-Meier survival analyses and (F) EPOCH cell-derived PB reconstitution of Rag- $2^{-l-} \gamma \mathrm{C}^{-/-}$mice undergoing transplantation with EPOCH cells fractionated for both $\mathrm{CD} 41$ and CD45 expression. Two independent experiments are presented. Error bars denote standard deviation. (G) CD41 and CD34 expression on EPOCH cells. (H) Kaplan-Meier survival analyses and (I) EPOCH cell-derived PB reconstitution of Rag- $2^{-1-} \gamma \mathrm{C}^{-1-}$ mice undergoing transplantation with EPOCH cells fractionated for CD34 expression are shown. Data in panel $\mathrm{H}$ summarize 4 experiments. Data in (I) summarize $7 \mathrm{CD} 34^{-}$recipients.

3 recipients of $\mathrm{CD}_{4} 8^{-}$cells and 5 of 6 recipients of $\mathrm{CD} 48^{+}$cells were rescued from lethal irradiation 4 weeks after transplant (Figure 6B; Table 3). Surprisingly, mice from both cohorts of animals maintained high EPOCH cell-derived PB chimerism for at least 26 weeks after transplant (Figure 6C; Table 3). These data suggest that ESC-HSCs can be found in both the $\mathrm{CD}_{4} 8^{-}$and $\mathrm{CD}_{4}{ }^{+}$subsets of EPOCH cells. We next examined CD41 high EPOCH cells for the coexpression of CD150 and CD48. CD41 high EPOCH cells nearly uniformly express CD150 (Figure 6D). Three distinct populations within this compartment can be clearly resolved on the basis of CD48 expression: CD48-/low CD48 ${ }^{\text {med }}$, and CD $48^{\text {high }}$. These 3 populations were purified by FACS and transplanted into Rag- $2^{-I-} \gamma \mathrm{c}^{-1-}$ recipients (Figure 6D). Each cohort was capable of rescuing mice from lethal irradiation and maintaining PB chimerism 22 to 29 weeks after transplant (Figure 6E-F; Table 3).

In summary, murine ESC-HSCs possess phenotypic hallmarks of developmental immaturity such as high CD41 expression and moderate CD45 expression, but like more mature FL and bone marrow HSCs, ESC-HSCs also express CD150 (Figure 7). Thus, ESC-HSCs present a unique cell-surface phenotype, distinct from any in vivo HSC population analyzed, that reflects a developmentally immature admixture of cells transitioning between embryonic and adult phenotypes. Furthermore, in sharp contrast to all in vivo HSC compartments, which lack CD48 expression, ESC-HSCs are heterogeneous with respect to CD48, with most of these cells expressing either moderate or high levels of this molecule (Figure 7).

\section{Discussion}

Here, we demonstrate that ESC-HSCs are CD41 ${ }^{\text {bright }}, \mathrm{c}-\mathrm{Kit}^{+}$, $\mathrm{CD}^{-} 4^{-}$, and heterogeneous for CD45. These data suggest that ESC-HSCs show greater similarity to early developmental HSC populations than adult WBM-HSCs. We have examined embryonic HSCs and ESC-HSCs for the cell-surface expression of CD48 and CD150, 2 members of the SLAM family of cellsurface molecules that have proven useful in high-purity prospective isolation of FL and WBM hematopoietic progenitors. ${ }^{30,31}$ We demonstrate that CD150 is developmentally regulated on the cell surface of embryonic HSC: it is absent on E9 YS, E11.5 AGM, and E12.5 placenta HSCs but present on E14.5 FL and WBM HSC. ESC-HSC also express CD150 but are heterogeneous for CD48 expression. 
From bloodjournal.hematologylibrary.org at ECOLE POLYTECHNIQUE FEDERALE DE LAUSANNE on March 25, 2014. For personal use only.

Table 3. Summary of ESC-HSC phenotype transplants

\begin{tabular}{|c|c|c|c|c|c|}
\hline EPOCH cell population & $\begin{array}{l}\text { No. of unfractionated } \\
\text { equivalents transplanted, } \\
\times 10^{6^{*}}\end{array}$ & $\begin{array}{c}\text { No. of cells } \\
\text { transplanted, } \times 10^{6}\end{array}$ & $\begin{array}{l}\text { No. of mice rescued at } \\
4 \text { wks after transplant/ } \\
\text { no. transplanted }\end{array}$ & $\begin{array}{c}\text { Peripheral blood } \\
\text { engraftment long-term† }\end{array}$ & $\begin{array}{l}\text { No. of animals displaying } \\
\text { multilineage engraftment }\end{array}$ \\
\hline $\mathrm{CD} 41^{+} \S$ & 3-5 & $1.9-4.4$ & $6 / 6$ & $15.5 \%-85 \%$ & 4 \\
\hline $\mathrm{CD} 41^{-} \S$ & 3-5 & $0.6-1.1$ & $0 / 6$ & & \\
\hline $\mathrm{CD} 45^{+} \S$ & $3-5$ & $1.4-2$ & $5 / 6$ & $1 \%-41 \%$ & 2 \\
\hline $\mathrm{CD} 45^{-} \S$ & 3-5 & $1.7-3$ & $6 / 6$ & $3.6 \%-64 \%$ & 2 \\
\hline CD $45^{+}$CD $41^{\text {low }} \S$ & $2-3$ & $0.14-0.3$ & $0 / 6$ & & \\
\hline CD45-CD41 $1^{\text {low }}$ & $2-3$ & $0.12-0.11$ & $0 / 6$ & & \\
\hline $\mathrm{CD} 45^{+} \mathrm{CD} 41^{\text {high }} \S$ & $2-3$ & $0.13-0.3$ & $5 / 6$ & $9.7 \%-63 \%$ & 1 \\
\hline $\mathrm{CD} 45^{-} \mathrm{CD} 41^{\text {high }} \S$ & $2-3$ & $0.4-0.5$ & $3 / 6$ & $83 \%-91 \%$ & 1 \\
\hline $\mathrm{CD}_{4}{ }^{+}$ & 2.5 & 0.125 & $0 / 3$ & nd & nd \\
\hline $\mathrm{CD}_{4} 4^{-}$ & 2.5 & 1.4 & $1 / 2$ & nd & nd \\
\hline $\mathrm{CD} 41^{+}{ }^{+} D 34+\S$ & $1.5-2$ & $0.023-0.3$ & $0 / 6$ & & \\
\hline $\mathrm{CD} 41^{+} \mathrm{CD} 34^{-} \S$ & $1.5-2.5$ & 0.3-0.9 & $4 / 4$ & $4.3 \%-91 \%$ & 3 \\
\hline $\mathrm{CD} 48^{-} \S$ & 5 & $1.75-1.8$ & $2 / 3$ & $8.4 \%-65 \%$ & 1 \\
\hline $\mathrm{CD}_{4} 8^{+} \S$ & 5 & $2.8-3.1$ & $5 / 6$ & $1.5 \%-90 \%$ & 3 \\
\hline CD41 high CD150+CD48-ๆ & $2-5$ & $0.016-0.4$ & $2 / 7$ & $7.2 \%$ & \\
\hline CD41 $1^{\text {high }} \mathrm{CD} 150^{+} \mathrm{CD} 48^{\mathrm{med}} \emptyset$ & $2-5$ & $0.35-0.75$ & $4 / 11$ & $2.4 \%$ & 1 \\
\hline CD41 high CD $150^{+}$CD48+9 & $2-5$ & $0.5-1$ & $6 / 9$ & $0.2 \%-14.4 \%$ & 3 \\
\hline
\end{tabular}

nd indicates not determined.

*Unfractionated equivalent numbers are calculated based on the frequency of each phenotypic subpopulation within the total EPOCH population. For example, $1 \times 10^{5}$ cells of a subset of cells representing $10 \%$ of the total population would be equivalent to 1000000 unfractionated EPOCH cells.

†Peripheral blood engraftment based on the frequency of green fluorescent protein-positive cells in the peripheral blood of surviving mice undergoing transplantation at $>18$ weeks after transplantation.

$\ddagger$ Multilineage engraftment is defined by the presence of cells in the PB of mice undergoing transplantation coexpressing green fluorescent protein and Mac-1 and/or Gr-1 (myeloid engraftment) and cells expressing CD19 and/or IgM (B cells) or CD3 and CD4/CD8 (T cells) $>22$ weeks after transplantation.

§Pooling of data from 2 independent experiments

IPooling of data from 4 independent experiments.

Before the current study, little was known regarding the basic biology of ESC-HSCs. Given that these cells are engineered from pluripotent cells predisposed to generate developmentally immature hematopoietic populations, ${ }^{20-26}$ a careful examination of the cell-surface phenotype of ESC-HSCs side by side with embryonic HSC compartments is crucial. By identifying cell surface markers that both allow for their prospective purification and their placement during HSC development, we can develop new strategies that allow us to direct these cells into adult-like WBM-HSCs.

HSCs are best defined functionally. Our EPOCH protocol allows for the robust and reproducible generation of cells from murine ESCs that meet a strict functional definition of HSCs: they rescue mice from lethal irradiation and maintain long-term chimerism. ${ }^{15}$ Most importantly, retroviral marking studies have demonstrated clonal multilineage $\mathrm{PB}$ repopulation of primary and secondary mice by ESC-HSCs engineered in this manner. ${ }^{15}$ The ability of HoxB 4 overexpression to induce the development of hematopoietic progenitors in differentiating human and mouse ESC is being actively explored by several groups. Cumulatively, the data suggest that the level of HoxB4 expression significantly affects the degree of hematopoietic specification, with moderate levels of HoxB4 expression optimal for hematopoietic induction. ${ }^{35-38}$ Significantly, hematopoietic repopulating cells derived from murine ESC via HoxB4 overexpression can induce tolerance in recipient mice, allowing for the acceptance of cardiac allografts. ${ }^{16}$ This system also allows for the derivation of repopulating cells from induced pluripotent cells, revealing that $H o x B 4$ overexpression can effect the derivation of ESC-HSCs from multiple pluripotent cell types. ${ }^{18}$ Given that this protocol is being broadly applied to both mouse and human pluripotent cell populations, better characterization of the resulting hematopoietic repopulating cells is imperative.
Our study represents a thorough characterization of the phenotype of EPOCH cell-derived ESC-HSCs. They express high levels of CD41, are c-Kit ${ }^{+}$and $\mathrm{CD} 150^{+}$, and lack CD34 expression (summarized in Figure 7). Surprisingly, EPOCH cells harbor a phenotypic mixture of ESC-HSCs as revealed by the heterogeneous expression of CD45 and CD48, although the most potent ESC-HSCs appear to express moderate levels of CD45. CD41 is a molecule that is expressed by HSC and progenitors in the YS, AGM, and placenta but is lost by the FL stage of development. ${ }^{3-5}$ In contrast, CD45 is not acquired by HSCs and progenitors until the late AGM stage of development. ${ }^{6}$ Although CD34 is expressed by most HSCs throughout development, $\mathrm{CD} 34^{-}$-repopulating cells have been detected in the AGM. ${ }^{7,39}$ Thus, ESC-HSCs phenotypically resemble HSCs that emerge early in development, suggesting that they themselves are developmentally immature. The apparent developmental immaturity of ESC-HSCs is consistent with the embryonic origin of the cells and perhaps reflects incomplete maturation or differentiation of the cultured cells. We are currently comparing the global gene expression profiles of purified ESC-HSCs with in vivo HSCs purified from throughout ontogeny in an attempt to more accurately define the developmental state of these in vitro derived cells. These studies will illuminate to which in vivo HSC compartment ESC-HSCs engineered in this context are most similar. Although, given their unique origin, it is very possible that ESC-HSCs will have no direct in vivo equivalent. However, by elucidating their cell-surface phenotype, we have provided a strategy by which these cells can now be prospectively purified and their biology studied in greater detail.

We have also demonstrated that CD150 is a developmentally regulated molecule on the surface of HSCs. Although WBM and FL HSC express CD150, a fact that we verified ourselves experimentally in this study, HSCs from the YS, AGM, and 


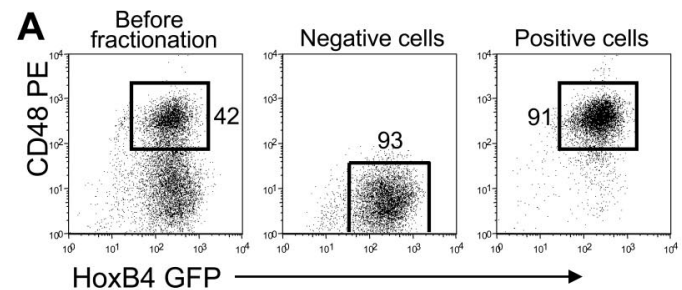

D

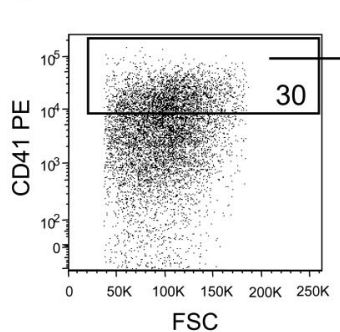

FSC

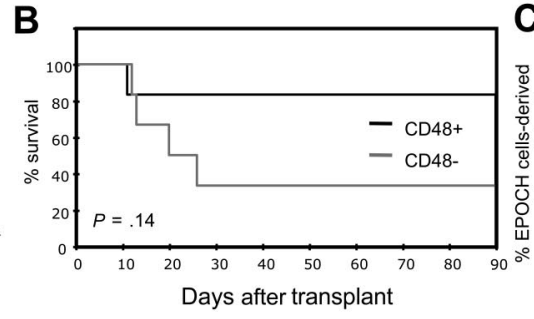

CD48-1low

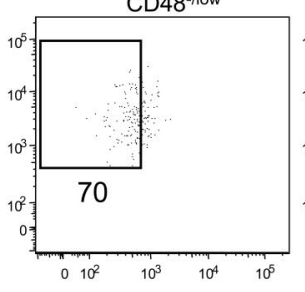

CD48med

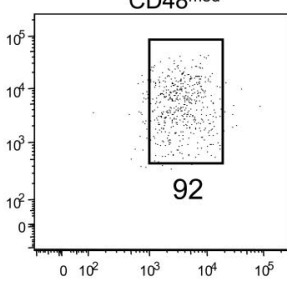

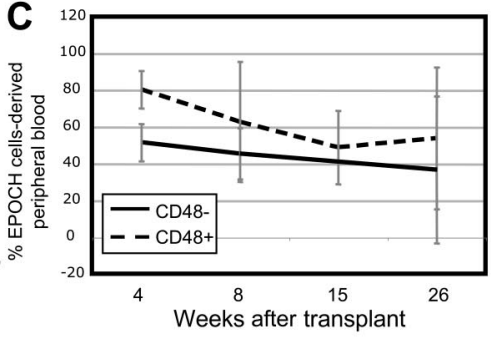

$\mathrm{CD} 48^{+}$
E

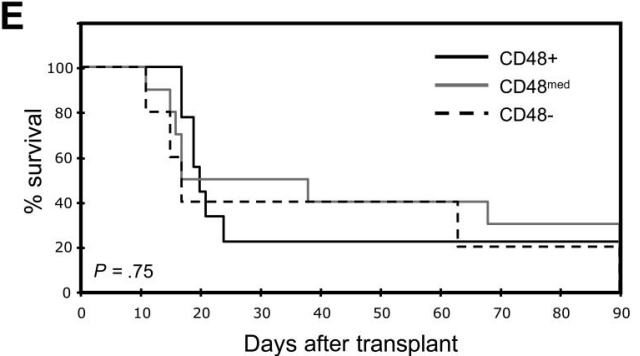

$\mathbf{F}$

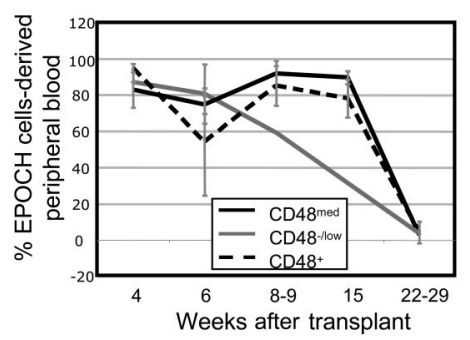

Figure 6. ESC-HSC are $\mathrm{CD}_{150}{ }^{+}$and heterogeneous with respect to $\mathrm{CD} 48$ cell-surface expression. (A) $\mathrm{CD}^{+} 8^{+}$and $\mathrm{CD} 48^{-} \mathrm{EPOCH}$ cells were isolated by magnetic bead selection and analyzed by flow cytometry before and after fractionation. (B) Kaplan-Meier survival analyses and (C) EPOCH cell-derived PB reconstitution of Rag- $2^{-1-} \gamma \mathrm{C}^{-1-}$ mice transplanted with $\mathrm{CD} 48 \mathrm{EPOCH}$ cells fractions. EPOCH cell-derived PB is GFP ${ }^{+}$. Data are pooled from 2 experiments. (D) $\mathrm{CD}^{4} 8^{-}$, $\mathrm{CD} 48^{\mathrm{med}}$, and $\mathrm{CD} 48^{+} \mathrm{CD}^{-} 1^{\text {high }}$ $\mathrm{CD}_{150}+\mathrm{EPOCH}$ cells were isolated via FACS. A representative before- and after-sort analysis is shown. (E) Kaplan-Meier survival analyses and (F) EPOCH cell-derived PB reconstitution of Rag- $2^{-1-} \gamma \mathrm{C}^{-1-}$ mice transplanted with $\mathrm{CD} 41^{\text {high }} \mathrm{EPOCH}$ cells fractionated for CD150 and CD48 expression are shown. Data are pooled from 4 experiments. Error bars denote standard deviation.

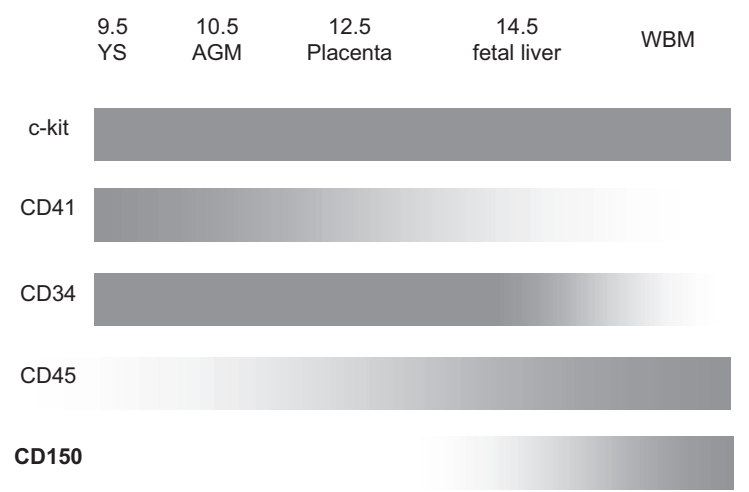

CD48 placenta do not (summarized in Figure 7). ${ }^{30,31}$ Thus, CD150 is acquired by HSC after the placenta stage of development. This finding adds to the repertoire of cell-surface molecules whose regulation can be studied to classify and characterize HSC at distinct developmental stages. Interestingly, although CD150 appears absent from the most developmentally immature HSC, it is expressed by ESC-HSCs. The expression of CD150 by this developmentally immature compartment could be a consequence of the extensive coculture of these cells with OP9 stroma (ie, the result of in vitro culture within an adult bone marrow microenvironment). Alternatively, the expression of CD150, in conjunction with the fact that ESC-HSCs are phenotypically heterogeneous with respect to CD45, suggests that EPOCH cells may consist of a pool of ESC-HSCs transitioning from a developmentally immature phenotype $\left(\mathrm{CD} 45^{-}\right)$to a developmentally mature phenotype $\left(\mathrm{CD} 45^{+} \mathrm{CD} 150^{+}\right)$. A CD $45^{-} \mathrm{CD} 150^{+}$ repopulating cell has never been identified in the murine embryo, perhaps because the transition from $\mathrm{CD} 45^{-} \mathrm{CD} 150^{-}$to $\mathrm{CD} 45^{-} \mathrm{CD} 150^{+}$may occur quickly in vivo and be too transient to capture via the methods used in the current study or may take place at an anatomic site not yet carefully examined for heterogeneity of CD45 expression (ie, the placenta). Finally, it is possible that the in vitro derivation of ESC-HSCs by the use of ectopic HoxB4 expression might result in a phenotype that does not formally correlate with an in vivo compartment.
Figure 7. Cell surface phenotype of embryonic and ESC-derived HSCs. Our data further defines the cell-surface phenotype of both murine ESC-HSCs and in vivo HSCs during ontogeny, especially with regard to the expression of the SLAM family of cell surface molecules. Similarly to early developmental HSC populations in the YS and AGM, ESC-HSCs express high levels of CD41. ESC-HSCs lack CD34 expression and are heterogeneous for both CD48 and CD45 cell-surface expression, suggesting that they represent a pool of phenotypically distinct repopulating cells. Surprisingly, we found that CD150 expression is developmentally regulated during HSC ontogeny; it is absent from E11.5 AGM and E12.5 placental HSCs but present on E14.5 FL and WBM HSC. CD48 was absent from HSCs throughout ontogeny. 
Our data also revealed that CD48 is absent from steady-state HSCs throughout development. We were never able to detect CD48 expression on repopulating cells in the E9 YS, E11.5 AGM, E12.5 placenta, or E14.5 FL, and CD48 is reportedly absent from WBM-HSCs. Thus, we were surprised by our observation that the majority of ESC-HSCs express this molecule. Recently, phenotypic HSC expressing CD48 have been detected in WBM after treatment with 5-FU or after in vitro culture. ${ }^{40,41}$ Multiple studies have shown that a greater proportional of these cells are in the $S / \mathrm{G}_{2} / \mathrm{M}$ phase of the cell cycle, although one study did not observe repopulating potential when these cells were transplanted. ${ }^{40,41}$ Although the expression of CD48 by ESC-HSCs suggests an actively cycling HSC population, our own preliminary analyses find no difference in the cell cycle status of $\mathrm{CD}_{4} 8^{+}$and $\mathrm{CD} 48^{-} \mathrm{EPOCH}$ cells. The majority $(>95 \%)$ of $\mathrm{CD} 41^{\text {bright }} \mathrm{CD} 150^{+} \mathrm{CD} 48^{+}$and $\mathrm{CD} 41^{\text {bright }} \mathrm{CD} 150^{+}$ CD $48^{-}$populations are in the $\mathrm{G}_{0} / \mathrm{G}_{1}$ phase of the cell cycle (data not shown). These data correlate with our observation that ESCHSCs lack CD34 expression (Figure 5; Table 3). Thus, CD48 does not appear to correlate strongly with repopulating potential in ESC-HSC populations.

Our study further establishes that ESCs are predisposed to generate developmentally immature hematopoietic populations in vitro. Although both murine and human ESCs can generate adult-type progenitors, as reported in some of the original work characterizing spontaneous hematopoietic differentiation of EBs, ${ }^{42,43}$ the authors of multiple studies ${ }^{20-26}$ have found that ESCs forced to generate large numbers of red blood cells and lymphocytes yield cells resembling these populations' immature counterparts. Furthermore, repopulating cells isolated from both human and mouse ESCs are transplanted most efficiently when introduced intrafemorally. ${ }^{12,38}$ These data suggest that ESC-derived cells are defective in homing to marrow after transplantation, similarly to what has been shown for pre-HSCs that emerge in the E9 YS. ${ }^{3}$ Inappropriate homing likely contributes to the apparent paucity of functional ESC-HSCs present within the EPOCH population. Preliminary studies reveal that although $\mathrm{CD} 41^{\text {high }} \mathrm{CD} 34^{-} \mathrm{EPOCH}$ cells are homogeneous for cell surface $\alpha 4 \beta 1$ intergrin expression, only a subset express CXCR4 (see supplemental Figure 9). Further work will be required to determine the functional significance of these observations.

Finally, it has recently been shown that cells with limited repopulating potential can be engineered from human ESCs via AGM-derived stromal cell coculture, suggesting that such cells are primed to respond to a developmental microenvironment. ${ }^{44}$ This work, in conjunction with our own, highlights the importance of developing strategies to induce the maturation of ESC-derived hematopoietic populations toward phenotypic and functional maturity such that they behave as bona fide bone marrow-derived HSCs. During the past several years, stromal cell lines isolated from distinct developmental microenvironments have been identified that can support HSCs in culture. ${ }^{45,46}$ Both mouse and human ESCs have been cultured with these lines, resulting in enhanced hematopoietic differentiation and the derivation of cells with limited repopulating potential from human ESCs. ${ }^{44,46}$ Recent work has begun to define the intermediate populations that emerge both during normal HSC development and during the in vitro differentiation of ESC along the hematopoietic lineages. For example, hematopoietic progenitors emerging in differentiating EBs transition through brachyury ${ }^{+}$and Flk-1 ${ }^{+}$intermediates as they progress from mesoderm to the hemangioblastic lineage. ${ }^{47}$ A study by Taoudi et $\mathrm{al}^{48}$ has demonstrated that most HSCs that emerge between E11.5 and E12.5 in the developing embryo are likely derived from a VE-cadherin ${ }^{+} \mathrm{CD} 45^{+}$precursor found in the intra-aortic clusters of the AGM. If the in vitro correlates to these key in vivo transitional populations were identified, then our strategy for directing the fate of differentiating ESCs toward HSCs could be refined by placing these populations in the appropriate developmental microenvironment and perhaps allowing for their complete maturation to WBM-like HSCs. Indeed, investigators have already begun to define the key signals promoting HSC maintenance emanating from these developmental stromal lines. ${ }^{49}$ In the meantime, the ESC-HSCs generated in our system remain a valuable tool for further study by allowing us to better understand the key pathways regulating both ESC differentiation and HSC development.

\section{Acknowledgments}

We thank Grigoriy Losyev (Division of Hematology/Oncology Flow Cytometry Core, Children's Hospital Boston, Boston, MA), John Daley (Hematologic Neoplasia Flow Cytometry Core, DanaFarber Cancer Institute, Boston, MA), and Suzan Lazo-Kallanian (Hematologic Neoplasia Flow Cytometry Core, Dana-Farber Cancer Institute, Boston, MA) for invaluable FACS support; Hanna Mikkola (Department of Molecular, Cell and Developmental Biology, University of California Los Angeles, Los Angeles, CA) for advice regarding placenta dissections and FACS analysis; Trista North (Division of Hematology/Oncology, Children's Hospital, Boston, MA) for demonstrating appropriate AGM and YS dissection techniques; and Michael Milsom (Division of Hematology/ Oncology, Children's Hospital Boston, Boston, MA) and Chad Harris (Division of Hematology/Oncology, Children's Hospital Boston, Boston, MA) for help with retroviral production. We also thank M. William Lensch of the Daley laboratory for comments on the manuscript.

This work was supported by the American Cancer Society (S.L.M.-F.), the Eleanor and Miles Shore Scholarship Program (S.L.M.-F.), the American Society of Hematology (S.L.M.-F.), the NIDDK (S.L.M.-F.), the Human Frontier Science Program Organization (S.L.), the Fundación Pedro Barrié de la Maza (O.N.), the Fondation pour la Recherche Medicale (F.Y.), additional National Institutes of Health (NIH) grants, the NIH Director's Pioneer Award, and the Burroughs Wellcome Fund Clinical Scientist Award in Translational Research (G.Q.D.).

\section{Authorship}

Contribution: S.L.M.-F., O.N., G.Q.D., and FY. designed the research and analyzed results; S.L.M.-F., O.N., F.Y., S.L., M.P., and M.C. performed experiments; S.L.M.-F. wrote the manuscript; O.N., S.L., and G.Q.D. edited the manuscript; and P.J.P. performed statistical analysis of the data.

Conflict-of-interest disclosure: The authors declare no competing financial interests.

Correspondence: George Q. Daley, Children's Hospital Boston, 300 Longwood Ave, Boston, MA 02115; e-mail: george.daley@ childrens.harvard.edu. 
1. Ratajczak MZ. Phenotypic and functional characterization of hematopoietic stem cells. Curr Opin Hematol. 2008;15:293-300.

2. Lensch MW, Daley GQ. Origins of mammalian hematopoiesis: in vivo paradigms and in vitro models. Curr Top Dev Biol. 2004;60:127-196.

3. Ferkowicz MJ, Starr M, Xie X, et al. CD41 expres sion defines the onset of primitive and definitive hematopoiesis in the murine embryo. Development. 2003;130:4393-4403.

4. Bertrand JY, Giroux S, Golub R, et al. Characterization of purified intraembryonic hematopoietic stem cells as a tool to define their site of origin. Proc Natl Acad Sci U S A. 2005;102: 134-139.

5. Mikkola HK, Fujiwara Y, Schlaeger TM, Traver D, Orkin SH. Expression of CD41 marks the initiation of definitive hematopoiesis in the mouse embryo. Blood. 2003;101:508-516.

6. North TE, de Bruijn MF, Stacy T, et al. Runx1 expression marks long-term repopulating hematopoietic stem cells in the midgestation mouse embryo. Immunity. 2002;16:661-672.

7. Ogawa M, Tajima F, Ito T, Sato T, Laver JH, Deguchi T. CD34 expression by murine hematopoietic stem cells: developmental changes and kinetic alterations. Ann N Y Acad Sci. 2001;938: 139-145.

8. Müller AM, Dzierzak EA. ES cells have only a limited lymphopoietic potential after adoptive transfer into mouse recipients. Development. 1993; 118:1343-1351.

9. Chen U, Kosco M, Staerz U. Establishment and characterization of lymphoid and myeloid mixedcell populations from mouse late embryoid bodies, "embryonic-stem-cell fetuses." Proc Natl Acad Sci U S A. 1992;89:2541-2545.

10. Brent L, Sherwood RA, Linch DC, Gale RE. Failure of embryonic mouse cells to engraft in immunocompetent allogeneic recipients. Br J Haematol. 1990;74:549-551.

11. Palacios R, Golunski E, Samaridis J. In vitro generation of hematopoietic stem cells from an embryonic stem cell line. Proc Natl Acad Sci U S A 1995:92:7530-7534.

12. Burt RK, Verda L, Kim DA, Oyama Y, Luo K, Link C Embryonic stem cells as an alternate marrow dono source: engraftment without graft-versus-host disease. J Exp Med. 2004;199:895-904.

13. Verda L, Kim DA, Ikehara S, et al. Hematopoietic mixed chimerism derived from allogeneic embryonic stem cells prevents autoimmune diabetes mellitus in NOD mice. Stem Cells. 2008;26:381 386.

14. Kyba M, Perlingeiro RC, Daley GQ. HoxB4 confers definitive lymphoid-myeloid engraftment po tential on embryonic stem cell and yolk sac hematopoietic progenitors. Cell. 2002;109:29-37.

15. Wang $Y$, Yates $F$, Naveiras $O$, Ernst $P$, Daley $G Q$. Embryonic stem cell-derived hematopoietic stem cells. Proc Natl Acad Sci U S A. 2005;102:1908119086

16. Bonde S, Chan KM, Zavazava N. ES-cell derived hematopoietic cells induce transplantation tolerance. PLOS ONE. 2008;3:e3212.

17. Chan KM, Bonde S, Klump H, Zavazava N. Hematopoiesis and immunity of HOXB4-transduced embryonic stem cell-derived hematopoietic progenitor cells. Blood. 2008;111:2953-2961.

18. Hanna J, Wernig M, Markoulaki S, et al. Treatment of sickle cell anemia mouse model with iPS cells generated from autologous skin. Science. 2007;318:1920-1923.

19. Rideout WM 3rd Hochedlinger K, Kyba M, Daley $\mathrm{GQ}$, Jaenisch R. Correction of a genetic defect by nuclear transplantation and combined cell and gene therapy. Cell. 2002;109:17-27.

20. Chang KH, Nelson AM, Cao H, et al. Definitivelike erythroid cells derived from human embryonic stem cells coexpress high levels of embryonic and fetal globins with little or no adult globin. Blood. 2006;108:1515-1523.

21. Olivier EN, Qiu C, Velho M, Hirsch RE, Bouhassira EE. Large-scale production of embryonic red blood cells from human embryonic stem cells. Exp Hematol. 2006;34:1635-1642.

22. Qiu C, Hanson E, Olivier E, et al. Differentiation of human embryonic stem cells into hematopoietic cells by coculture with human fetal liver cells recapitulates the globin switch that occurs early in development. Exp Hematol. 2005;33:1450-1458

23. Zambidis ET, Peault B, Park TS, Bunz F, Civin Cl Hematopoietic differentiation of human embryonic stem cells progresses through sequential hematoendothelial, primitive, and definitive stages resembling human yolk sac development. Blood. 2005;106:860-870.

24. Galic Z, Kitchen SG, Kacena A, et al. T lineage differentiation from human embryonic stem cells. Proc Natl Acad Sci U S A. 2006;103:1174211747

25. Martin $\mathrm{CH}$, Woll PS, Ni Z, Zuniga-Pflucker JC, Kaufman DS. Differences in lymphocyte developmental potential between human embryonic stem cell and umbilical cord blood-derived hematopoietic progenitor cells. Blood. 2008;112:2730-2737.

26. Vodyanik MA, Bork JA, Thomson JA, Slukvin II. Human embryonic stem cell-derived CD34+ cells: efficient production in the coculture with OP9 stromal cells and analysis of lymphohematopoietic potential. Blood. 2005;105:617-626.

27. Tavian M, Robin C, Coulombel L, Peault B. The human embryo, but not its yolk sac, generates lympho-myeloid stem cells: mapping multipotent hematopoietic cell fate in intraembryonic mesoderm. Immunity. 2001;15:487-495.

28. McKinney-Freeman SL, Lengerke C, Jang IH, et al. Modulation of murine embryonic stem cellderived CD41+c-kit+ hematopoietic progenitors by ectopic expression of Cdx genes. Blood. 2008 111:4944-4953.

29. McKinney-Freeman SL, Naveiras O, Daley GQ. Isolation of hematopoietic stem cells from mouse embryonic stem cells. Current Protocols in Stem Cell Biology. Malden, MA: Wiley; 2008. Chapter 1:Unit 1F.3.

30. Kiel MJ, Yilmaz OH, Iwashita T, Yilmaz OH, Terhorst C, Morrison SJ. SLAM family receptors distinguish hematopoietic stem and progenitor cells and reveal endothelial niches for stem cells. Cell. 2005;121:1109-1121.

31. Kim I, He S, Yilmaz OH, Kiel MJ, Morrison SJ. Enhanced purification of fetal liver hematopoietic stem cells using SLAM family receptors. Blood. 2006; 108:737-744.

32. Gekas C, Dieterlen-Lievre F, Orkin SH, Mikkola HK. The placenta is a niche for hematopoietic stem cells. Dev Cell. 2005;8:365-375.

33. Basch RS, Oh YD, Saha CS, Fredrickson GG, Hirst JA. Separation of self-renewing hematopoietic progenitors on the basis of CD45 (T-200) antigen expression. Exp Hematol. 1992;20:11-16.

34. Craig W, Poppema S, Little MT, Dragowska W,
Lansdorp PM. CD45 isoform expression on human haemopoietic cells at different stages of development. Br J Haematol. 1994;88:24-30.

35. Bowles KM, Vallier L, Smith JR, Alexander MR, Pedersen RA. HOXB4 overexpression promotes hematopoietic development by human embryonic stem cells. Stem Cells. 2006;24:1359-1369.

36. Unger C, Kärner E, Treschow A, et al. Lentiviralmediated HoxB4 expression in human embryonic stem cells initiates early hematopoiesis in a dosedependent manner but does not promote myeloid differentiation. Stem Cells. 2008;26:2455-2466.

37. Ji J, Vijayaragavan K, Bosse M, Menendez P Weisel K, Bhatia M. OP9 Stroma augments survival of hematopoietic precursors and progenitors during hematopoietic differentiation from human embryonic Stem Cells. Stem Cells. 2008;26: 2485-2495.

38. Wang L, Menendez P, Shojaei F, et al. Generation of hematopoietic repopulating cells from human embryonic stem cells independent of ectopic HOXB4 expression. J Exp Med. 2005;201:1603 1614.

39. Sánchez MJ, Holmes A, Miles C, Dzierzak E. Characterization of the first definitive hematopoietic stem cells in the AGM and liver of the mouse embryo. Immunity. 1996;5:513-525.

40. Venezia TA, Merchant AA, Ramos CA, et al. Molecular signatures of proliferation and quiescence in hematopoietic stem cells. PLoS Biol. 2004;2: e301.

41. Noda S, Horiguchi K, Ichikawa H, Miyoshi H. Repopulating activity of ex vivo-expanded murine hematopoietic stem cells resides in the CD48-C$\mathrm{Kit}+\mathrm{Sca}-1+$ lineage marker- cell population. Stem Cells. 2008;26:646-655

42. Kaufman DS, Hanson ET, Lewis RL, Auerbach R, Thomson JA. Hematopoietic colony-forming cells derived from human embryonic stem cells. Proc Natl Acad Sci U S A. 2001:98:10716-10721.

43. Wiles MV, Keller G. Multiple hematopoietic lineages develop from embryonic stem (ES) cells in culture. Development. 1991;111:259-267.

44. Ledran MH, Krassowska A, Armstrong L, et al. Efficient hematopoietic differentiation of human embryonic stem cells on stromal cells derived from hematopoietic niches. Cell Stem Cell. 2008, 3:85-98.

45. Oostendorp RA, Harvey KN, Kusadasi N, et al Stromal cell lines from mouse aorta-gonadsmesonephros subregions are potent supporters of hematopoietic stem cell activity. Blood. 2002; 99:1183-1189.

46. Krassowska A, Gordon-Keylock S, Samuel K, et al. Promotion of haematopoietic activity in embryonic stem cells by the aorta-gonad-mesonephros microenvironment. Exp Cell Res. 2006;312:35953603.

47. Fehling HJ, Lacaud G, Kubo A, et al. Tracking mesoderm induction and its specification to the hemangioblast during embryonic stem cell differentiation. Development. 2003;130:4217-4227.

48. Taoudi S, Gonneau C, Moore K, et al. Extensive hematopoietic stem cell generation in the AGM region via maturation of VE-cadherin + CD45+ pre-definitive HSCs. Cell Stem Cell. 2008;3:99108.

49. Durand $\mathrm{C}$, Robin $\mathrm{C}$, Bollerot $\mathrm{K}$, Baron $\mathrm{MH}$, Ottersbach K, Dzierzak E. Embryonic stromal clones reveal developmental regulators of definitive hematopoietic stem cells. Proc Natl Acad Sci U S A. 2007; 104:20838-20843. 